\section{$\Omega$}

Renata L. Riha

(1]

Department of Sleep Medicine, Royal Infirmary Edinburgh, Edinburgh, UK.

\title{
Breathe: new features and new ways to get involved
}

\section{Welcome to the December issue of Breathe!}

As incoming Chief Editor, I would like to start by thanking Dr James Paton, outgoing Chief Editor, for taking the journal through three exciting years packed with interesting, informative and practical articles and overseeing the further integration of our more junior colleagues through a popular and successful collaboration with the European Respiratory Society Junior Members Committee.

Breathe reaches an international audience both in print and online (breathe.ersjournals.com); and thanks to the efforts of the editorial team, Breathe is now available via PubMed Central, increasing its distribution and visibility.

Primarily a publication dedicated to education, Breathe aims to provide information to the whole respiratory team, and I hope, across the forthcoming issues that there will be something of interest for everyone. Over the next three years, the aim will be to integrate and link the material in the print issues of Breathe to a greater online presence and I hope that you, the readers, will support us in this endeavour!

This issue deals with various respiratory problems that may occur or be exacerbated by the normal physiological state of pregnancy. I don't know about you, but I find it just as terrifying stepping onto the obstetrics ward as the obstetrician does stepping onto a respiratory ward; although the latter rarely happens! However, respiratory problems do not go away during pregnancy and there are issues to consider when treating these patients. We have some excellent contributions from experts in the field and I am grateful to them for bringing so much thought and consideration to the subjects they address.

\section{New features}

You will hopefully notice that we have introduced some new features to the pages of Breathe, including the Physiology Masterclass, an area fundamental to our specialty, as well as the Radiology Corner which brings some excellent educational cases for self assessment from the European Respiratory Society.

\section{Chances to get involved}

The interactive case report remains an important part of Breathe's portfolio and we encourage as many submissions of interesting and instructive cases for publication. Those that don't make it into the pages of a printed issue can be published online as part of our expanding presence, and can therefore still be accessed via PubMed Central and reach a large audience. As such, we will be hosting an annual competition to authors of case reports. The author of the best case report each year will be awarded their choice of ERS Handbook or ERS Monograph. Full details, as well as terms and conditions, can be found online at breathe.ersjournals.com.

Speaking of competitions, we would like to encourage all readers to assist with enhancing the pages of Breathe by submitting their own photographs and art related to the world of lung

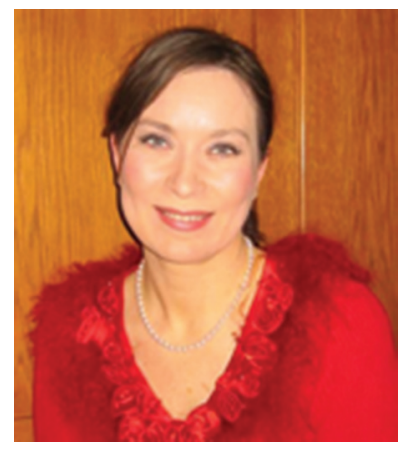

Cite as: Riha RL. Breathe: new features and new ways to get involved. Breathe 2015: 11: 247-248. 
health, disease, clinical care, management and research. I am certain that there are many unrecognised artists out there and we would love to showcase your work! Our next issue will focus on respiration at the extremes of age, so start sending in your work now for a chance to have it published in the March issue.

\section{Discover more about the people behind ERS}

No doubt you will enjoy finding out a bit more about our Assemblies and the leadership of
ERS; for this reason, we have introduced a Meet the Assemblies feature, starting this issue with Assembly 8, and our own Confidences de Salon, an intimate questionnaire to allow us to better understand the personalities and motivations of the people involved in ERS. Like Marcel Proust did over a hundred years ago, ERS President, Prof. Jørgen Vestbo, has offered up his answers; thank you for leading the way!

Finally, as the festive season approaches, I would like to wish everyone a safe and enjoyable break and happy reading!

\section{Conflict of interest}

None declared. 